\title{
Use of Complementary or Alternative Medicine in Patients with Cancer in Turkey
}

\author{
Elvan Akgul $^{1}$ and Mine Dosay-Akbulut ${ }^{2}$ \\ 1. Department of Physiotherapy, University of Afyon Kocatepe, Afyon 03200, Turkey \\ 2. Department of Medical Biology and Genetics, University of Afyon Kocatepe, Afyon 03200, Turkey
}

\begin{abstract}
Cancer is one of the major mortality factors for our country and worldwide. In treatment of this illness, additional to standard methods, CAM (complementary and alternative medicine) as alternative and supporting treatments increasingly draws attention. In this study, understanding CAM methods and their usage levels in our country were searched on basis of questionnaire data. The collected data were analyzed using SPSS statistical software package. The importance degree was analyzed using Fisher's exact test and chi-square test. In our findings, $69 \%$ of all patients were receiving the CAM methods and the highest using level was obtained from nettle with 56.6\%. The relations between using of CAM were also determined by the educational and economical income levels. According to our results, the CAM methods gained more importance and their usage increased in Turkey. Also, in the world, the use of these methods increases day by day, hence several different countries replace CAM methods from alternative treatment class with the main treatment methods.
\end{abstract}

Key words: Alternative medicine, CAM, cancer, statistics, questionnaire.

\section{Introduction}

Currently, one of the most known health problems is cancer. Five most common types of cancer for both genders can be listed as stomach, lung, breast, colon-rectum and cervix cancer. Incidence of these cancer types significantly varies with respect to the following factors such as age, sex, organ that is the source of cancer and other environmental factors.

Alternative medicine techniques have been developed instead of known cancer treatments and become an increasingly widely used method all over the world while time is passing. CAM (complementary and alternative medicine) techniques, placed in the alternative medicine, is densely being used for treatment of various types of incurable illness and also as an additional treatment to the chemotherapy in cancer treatment.

Usage of CAM has increased especially in many

Corresponding author: Mine Dosay-Akbulut, Ph.D., associate professor, research field: molecular systematic. E-mail: minedosay@aku.edu.tr. developing and industrialised countries. the CAM usage ratios are $42.1 \%$ in USA, $48.2 \%$ in Australia, 49.3\% in France, and $70.4 \%$ in Canada [1].

Researches show that $1 / 3$ of Americans use CAM in order to meet their health care requirements additional to their standard conventional treatments [2].

Another study indicated that according to analysis of questionare data in Australia, 65\% of cancer patients used at least one form of CAM. Up to $90 \%$ of CAM users believed that CAM provided potential health benefits and less than $3 \%$ stated that side effects caused by using of CAM [3].

CAM techniques have become widespread especially for cancer patients. More space given to the CAM techniques by the media, the low rate of success in traditional treatment or the increasing interest to the completely natural treatments may be the reasons of the increasing interest to the CAM techniques by the cancer patients.

One survey study determined that $56 \%$ of patients consumed some type of CAM during active anti-cancer 
therapy. Within these CAM users, most of them (52\%) used herbal teas and vitamins. Majority of them (85\%) believed that supplementary products increase the efficacy of standard anti-cancer therapy and extend their survival. Information was obtained from mainly internet sources (36\%), books and brochures (25\%) [4].

The researchs about the frequency of cancer have been showing that environmental factors and individual habits contributes to the improvement of cancer. Genotype and environmental factors play an important role in awaking of cancer. It has been estimated that half of all types of cancer were awaked with environmental effects. These environmental factors can be determined as radiation, physical or chemical agents, sun light, usage of tobacco and making diet [5].

Surgical treatment, radiotherapy, chemotherapy and immunotherapy are the widely used types of cures for cancer treatment.

Since there is an increasing interest by the public to CAM methods, the US government established NCCAM (The National Center for Complementary and Alternative Medicine) in 1998 to make researches and give advices about the CAM methods. NCCAM has proped specific classification system, including group of diverse medical and health care systems, practices, and products that are not generally considered part of conventional medicine. According to this classification, CAM methods have been examined in five groups [2]:

(1) Alternative medicine systems: They are east medical methods as Ayurvedic medicine, traditional Chinese medicine, traditional Tibet medicine and also methods progressed in west such as homeopathy and naturopathy.

(2) Mind-body medicine: They are methods aiming to effect the health of body with mental applications. art therapy, meditation, NLP (neuro linguistic programming) and yoga.

(3) Biologically based therapy: Plants, vitamins, diets and other natural products are in this class. Especially, vegetal drugs such as echinacea, ginseng, gingko, thyme, nettle grass, brocoli, brussel sprout, senna, green tea and aloe vera which have been used for treatment mostly by the cancer patients.

(4) Manipulative and body based methods: They are methods depended on the motion of body. Shiropractic, osteopathy, Cranio sacral therapy, massage, Alexander Technic are such types of methods.

(5) Energy Therapies: There are two types of energy therapy. First is the therapy applied with magnets and variable or direct current areas. These are called as bio-electromagnetic therapies. Second energy therapy is the bio-area therapies. In this classification, acupunctur, acupresur, bioenergy, gi gung, reflexology, reiki, shiatsu, ta and chi are included [6].

The use and importance of CAM increase in the world every day and CAM becomes main treatment method instead of alternative. It is important to understand what the situation is in Turkey as a developing country. To search which CAM method is preferred, and the levels of usage in our country, the questionnaire data were applied and results were statistically analyzed.

\section{Materials and Methods}

\subsection{Form of Research}

The objective of this study is to determine the usage level of complementary and alternative medicine of the cancer patients in Turkey. For this aim, a survey was applied to the patients, treated in oncology hospitals or oncology clinics of medicine faculty hospitals or in goverment hospitals collected from two cities of each regions.

\subsection{Research Location}

Survey included all regions of Turkey and was applied to two cities from each region (Ankara and Eskisehir from middle Anatolia region, Izmir and Afyonkarahisar from Aegean region, Trabzon and Zonguldak from Blacksea region, Istanbul and Bursa from Marmara region, Antalya and Mersin from Mediteranean region, Erzurum and Elazıg from east 
Anatolia region, and Gaziantep and Diyarbakir from southeast Anatolia region) between 1st of January 2008 and 1st of January 2009. These regions have been shown in map below with yellow color.

\subsection{Selection of Universe and Epitome}

The survey applied to 30 patients from 14 cities, and total 420 patients results were obtained. Survey form has formed from six parts. In the first part about the patients' individual information, in second part about CAM method they used and their usage frequency, in third part using reason, in part four the expected result, in part five cost of CAM methods, in part six whose suggestion was asked. Total 16 questions were included.

\subsection{Statistical Analysis}

SPSS for Windows Release 11.0.0 packet programme has been used for the analysis of collected data. Fisher exact and chi-square tests were applied to data.

\section{Results}

The survey data have been obtained from 214
(50.9\%) male and 206 (49.0\%) female patients. Mostly seen types of cancer were GIS (gastro istestinal system) cancer with $31.1 \%$ and breast cancer with $19.5 \%$ as it was shown in Table 2.

According to our results, the most preferred standard treatment is chemotheraphy with $89.7 \%$, radiotheraphy with 30.7\%, surgical treatment with $55 \%$ and immunotheraph with $20 \%$.

Distribution of cancer types seen in Turkey with respect to the regions have been shown in Fig. 2 . The highest seen cancer types for each region have been presented together. The breast cancer in southeast Anatolia region, in east Anatolia and in Mediterranean region; the GIS in middle Anatolia, in Aegean region and in Blacksea region has been seen in highest level. We have been thinking that the diversity of the cancer types between the regions is directly dependent on the social, cultural, economic and educational levels and also on the diversity of their living type and eating quality.

Patients using CAM methods have been explaining the reason of trying these methods differently. The most given answer was determined as increasing the resistance of body against cancer (38.8\% of all cancer

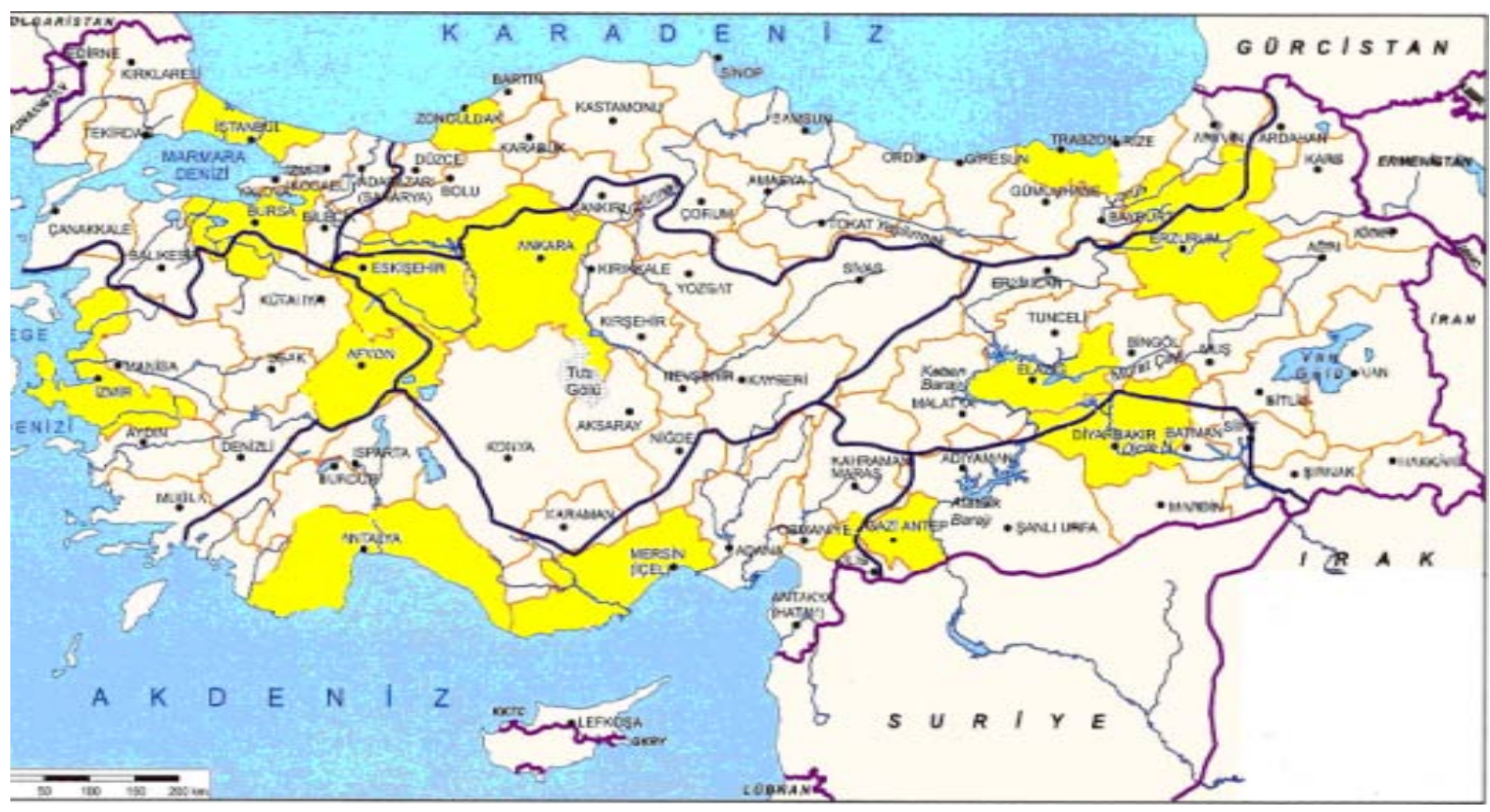

Fig. 1 Turkey map

(Source: www. archives.php/Turkiye-Bolgeler-Haritasi/2343-5k.). 
Table 1 Survey form.

\begin{tabular}{ll}
\hline Questions & Answers \\
\hline 1. Individual informations about patients & \\
\hline
\end{tabular}

1. Individual informations about patients

(a) $0-20$

1.1 Age

(b) 20-40

(c) More than 40

1.2 Sex

(a) Male

(b) Female

1.3 Educational status

(a) Illiterate

(b) Graduated from primaryschool

(c) Graduated from highschool

(d) Graduated from University or Upper

(a) Married

1.4 Civil status

(b) Single

(c) Divorced

(d) Partner dead.

(a) Housewife

(b) Independent bussiness

(c) Government official

1.5 Profession

(d) Private sector staff

(e) Retired

(f) Unoccupied

(g) Student.

(a) Lower than 10 billion

1.6 Annual revenue per one person

(b) 10-20 billion

(c) More than 20 billion

1.7 Type of ilness

Please write your cancer type

1.8 Taken standard treatment method

(a) Chemotheraphy

(b) Radiotheraphy

(c) Surgery treatment

(d) Immunotheraphy

2. Used complimentary and alternative medical methods and frequency

Aromatic Treatment

Hypnotism

Rubbing with hand

Religious treatments

Natural treatment

Animal sourced products

Medical tea

Acupuncture

Cancer diets

2.1 Mark the methods that you have used

Massage treatment

Electromagnetic treatment

Relaxation

Yoga

Taking vitamin/mineral

Vegetal treatment

Reiki

Imaginary animation

Physical treatment

Types co-enzymes

2.2 Write name of method you used if there is else

(a) Begining.

(b) During treatment process.

2.3 In which stage of the ilness you have tried these methods

(c) When you understood that treatment wont be successfull at the end of treatment.

(a) When I found opportunity

(b) 1-2 times a week

2.4 How often you have tried these methods

(c) 1-2 times a month

(d) 1-2 times a year

(e) I have just tried once 
(Table 1 Continued)

\begin{tabular}{|c|c|}
\hline Questions & Answers \\
\hline 3. Mark the reasons made you use these methods & $\begin{array}{l}\text { Direct struggle with ilness } \\
\text { Increasing the resistane of body during contention with cancer } \\
\text { Amending the physical view } \\
\text { Providing emotional improvement } \\
\text { Expectation and positive thinking } \\
\text { Not to suffer } \\
\text { Reducing the effect of ilnesses } \\
\text { Trying anything against cancer }\end{array}$ \\
\hline 4. Have you met the result you expected? & $\begin{array}{l}\text { (a) I got the result I have expected } \\
\text { (b) I have not seen any benefit } \\
\text { (c) I have not taken the result yet } \\
\text { (d) I have not been treated but it resulted a relaxation on me }\end{array}$ \\
\hline 5. What is the cost of the methods you have used & $\begin{array}{l}\text { (a) Cheaper compared to the medical treatment } \\
\text { (b) More expensive than medical treatment } \\
\text { (c) Almost same with medical one } \\
\text { (d) No cost }\end{array}$ \\
\hline 6. Whose suggestions made you try these methods & $\begin{array}{l}\text { (a) Family members } \\
\text { (b) Self information } \\
\text { (c) Relatives } \\
\text { (d) Friends } \\
\text { (e) Neigbours } \\
\text { (f) Newspaper, review, internet, publishment branches } \\
\text { (g) Doctor, nurse, medical staff etc. }\end{array}$ \\
\hline
\end{tabular}

Table 2 The cancer patient percentage in Turkey.

\begin{tabular}{lll}
\hline Recognition & Number of people & $\%$ \\
\hline Breast cancer & 82 & 19.5 \\
Gís cancer & 131 & 31.1 \\
Gynecological cancer & 30 & 7.1 \\
Propogation system cancer & 32 & 7.6 \\
Lung cancer & 56 & 13.3 \\
Hematological cancer & 38 & 9.0 \\
Other types of cancer & 51 & 12.1 \\
\hline
\end{tabular}

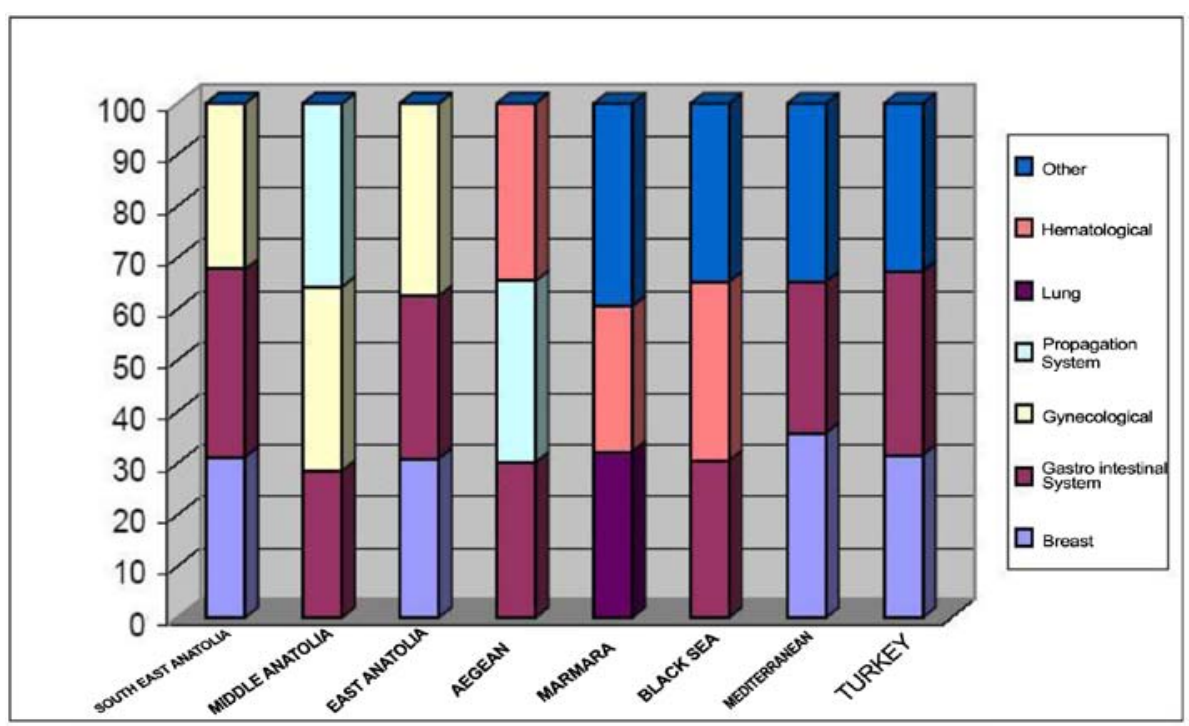

Fig. 2 Cancer types releated to regional distribution. 
Table 3 CAM methods used in Turkey.

\begin{tabular}{llll}
\hline Types of CAM used & Number of person & $\begin{array}{l}\text { Refers to how many percent of } \\
\text { CAM users }\end{array}$ & $\begin{array}{l}\text { Refers to how many percent of } \\
\text { CAM users }\end{array}$ \\
\hline Physical treatment & 25 & 8.6 & 5.9 \\
Religious treatments & 58 & 20 & 13.8 \\
Ache preventers & 14 & 4.8 & 3.3 \\
Massage treatment\& rubbing & 29 & 10 & 6.9 \\
Taking vitamin and mineral & 92 & 31.7 & 21.9 \\
Yoga, reiki, meditation & 28 & 9.6 & 6.6 \\
Cancer diets & 16 & 5.5 & 3.8 \\
Appeal to a psychiatrist & 20 & 6.8 & 4.7 \\
Sport activities & 18 & 6.2 & 4.2 \\
Non-vegetal components & 47 & 16.2 & 11.1 \\
(a) Royal jelly & 16 & 55 & 3.8 \\
(b) Pine honey & 9 & 3.1 & 2.1 \\
(c) Honey & 19 & 6.5 & 4.5 \\
(d) Cod-liver oil & 19 & 6.5 & 4.5 \\
Other & 14 & 4.8 & 3.3 \\
Vegetal treatment \& medical tea & 196 & 67.5 & 46.6 \\
\hline
\end{tabular}

patients and $56.2 \%$ of patients using CAM methods). It was determined that $69.4 \%$ of cancer patients in Turkey have been using at least one of the CAM methods. The highest percent in using of CAM has been obtained with $83.3 \%$ in Blacksea region; while the lowest level with $61.6 \%$ in Aegean and Mediterranean regions.

As it can be easily seen from Table 3, it was found that in our country, vegetal treatment and medical tea are the most preferred CAM method and the same result was also obtained in regional surveys. Within the vegetal herbs, nettle was used in majority region.

Cancer patients spent different amount of money for these treatments except medical treatment. However, most of cancer patients (20.4\% of cancer patients and $29.6 \%$ of patients using CAM methods) have defined that they did not spend any money. As a advicer of these methods most of the patients (34\% of cancer patients and $49.3 \%$ of CAM users) indicated that these informations belonged to family members. The interesting result is that printed sources did not effect the usage of CAM as it was supposed. In west regions, which the social-cultural living is highly active, the effect of press publication on spreading of CAM usage could be seen easily. But there is another interesting result in Turkey that during determining and encouraging of the CAM methods, effect of doctors, nurses and medical staff are significantly low.

In none of our data analysis, significant differences have been found (according to the chi-square and significant level of $P$ ) same to similar research carried out in Turkey and in abroad, with ignorable differences.

Satisfied patients' number was very low and this result was not so amazing, because CAM methods consist the alternative methods and no information has reported about any completely treated cancer type by just using one of these methods. Generally, these CAM methods applied only for aiming emotional relaxation or to increase the resistance of immune system.

\section{Discussion}

Cancer patients those participated to survey preferred primarily traditional methods, then took CAM into consideration. A lot of researchs were carried out to determine the CAM method using ratios in different countries. Most of them gave similar result to ours.

The aim of Algier LA and his friend was to determine which CAM methods were preferred by 
cancer patients? Study was done on 100 patients of two hospitals. Inspite the fact that these 100 patients were being treated by traditional treatment, $36 \%$ of them have used CAM methods as well. Generally, women and insufficient educated patients have prefered CAM compared to others. The most preferred treatment method was vegetal therapy like that in our study [7].

In another study that was carried out with 111 lung cancer patients from eight countrys in Europe, it was determined that $23.6 \%$ of cancer patients used CAM methods. The most used CAM method was vegetal treatment with the ratio of $48.1 \%$. Especially, after learning that they are cancer patients, the CAM using ratio have increased three times more than normal [8]. Different studies were carried out in Israel to determine the CAM method using possibilities. The CAM method using ratio was $32.4 \%$. The most used CAM method was the vegetal treatment with $22.2 \%$. After vegetal treatment, relaxation methods such as yoga, reiki and religious methods come to front with the effect of different social, economic and cultural diversities between two countries. The main effects come from family, friends and media, same with our findings [9].

In another study, the reasons why 143 cancer patients are using CAM has been examined between the patients who have different ethnic roots in USA. Results have shown that at least three different CAM methods were used and mostly preferred methods were vegetal treatment and supporting vitamin taking. They indicated that the reason of using these methods were an alternative to standard cancer treatment since CAM is less destructive, having no harmfull effects and make them relax physicologically [10].

In a study belonging to Kav et al. [11], cancer patients' usage ratio of CAM methods have been found between $22.1 \%$ and $84.1 \%$, and the average value has been calculated as $46.2 \%$.

Another study of six countries including Turkey in the middle east, by Ben-Arye et al. [12] indicated that CAM methods were used very often but it is still accepted as a supporting method not the main method, which is the same with our results.

Another study was done with 153 participants. The aims of this study were to evaluate the frequency of CAM use among radiation oncology patient. The two most frequent diagnoses were breast cancer (43.8\%) and prostate cancer (22.9\%). CAM use was reported in 95\% of the participants. The spiritual healing/prayer, followed by multivitamins were the most commonly reported as a CAM method. Patients reported that they are using CAM with the affection of previous users and physician recommendation. The recommendation of the healthcare providers was relatively low [13].

Different studies were carried out with Thai breast cancer patients. In this study, it was described that how Thai nurses perceive the use of CAM in survivors. An ethno-nursing research method was used. Fifteen Thai nurses were interviewed. Two findings were obtained related to CAM use as: (1) an extra beneficial choice for health; (2) emotional and psychological healing similar to our result [14].

Another study was based on the determination of CAM using ratio, reason and type within the Irish pediatric cancer patients. As a result, 42 respondents (57\%) said their child had used or was using CAM. The most common types of CAM were vitamins and minerals similar to our findings. The most common reason to use CAM was to improve physical well-being (31\%). 86\% of CAM users reported benefit from the treatment with no side effects. CAM using ratio was effected positively from the patients or their family education level similar to our findings [15].

Another study carried out to determine the CAM using reasons and the frequency within the cancer patients in Morocco. Study included questionnaire data analysis of 400 patients. The results indicated that $71 \%$ of patients were using CAM. Mostly religious therapy (60\%) was applied. The second one was herbal medicine (36\%). The main reason in using CAM was reducing psychic pain with $53 \%$ and supporting of the immune system with 32\% like our result. The side effects were reported in $2 \%$ of cases only [16]. 
Another study investigated the CAM using ratio and reasons within the advanced cancer patients in Germany. For this aim, 25 patients and 25 relatives of those patients were interviewed. $40 \%$ of all patients used at least one CAM methods, supplements and prayer. CAM was preferred for mainly to retain individuals' own strength and to be able to do something by oneself. The information obtained from television/radio (48\% and 28\%), family/friends (40\% and $48 \%$ ) and from the internet (40\%) but not mainly from the hospital workers was similar to ours [17]. Different studies included a survey of medical oncology outpatients. Among 316 participants, 193 (61.3\%) reported CAM use after diagnosis. The female gender $(P=0.005)$; person with college or higher education ( $P=0.09$ ); person with breast cancer diagnosis $(P=0.016)$; and being 12 to 36 months post-diagnosis ( $P=0.017)$ preferred significantly the CAM methods in concordance with our results. Most preferred ones were energy healing and healing arts with higher benefits. Special diet, herbal remedies, vitamin use and massage provided less benefit compare to others [18].

The prevalence, pattern and predictors of CAM use in cancer patients in Ghana were investigated with questionnaire data analysis of cancer patients, who were receiving radiotherapy and/or chemotherapy or completed their treatment recently. $73.5 \%$ of the participants were CAM users with preferring mostly massage (66.3\%), herbal (59.2\%), mega vitamins (55.1\%), Chinese medicine (53.1\%) and prayer (42.9\%). Overlapping toxicity was reported. Women, palliative patients, young, married and highly educated individuals are more likely to use CAM similar to our results. The main sources of CAM were friends and media [19].

In other study, the prevalence and types of CAM used by cancer patients with receiving chemotherapy in Taiwan were searched. In the result, the vast majority of the patients used CAM with $98.1 \%$. The two most preferred types were biologicaly based therapied which uses substance found in the nature such as botanicals, animal-derived extracts, vitamins and minerals (77.5\%) and mind body interventions (60.6\%). The most commonly reported reasons to use CAM were boost the immune system (55.4\%) and relieve the stress (53.5\%). This research determined that high level use of CAM by the cancer patients in Taiwan and the types of CAM differed from the western countries [20].

\section{Conclusion}

As it can be easily seen from all of these studies, CAM as the alternative and supporting treatment can be used by patients additionally to the known standard treatment of illness such as cancer which can derive from fatal results. Our survey which applied to all regions of our country supports this results and proves that mostly preferred CAM treatment is vegetal treatments and nettle is standing out among them. However, observations show that, despite increased use of CAM methods in the world and in Turkey, it is still seen as an alternative treatment in Turkey and patients prefer them just to try against to cancer. The reason of this is thought to be the lack of patients' knowledge or lack of encourage comes from medical staff. Since CAM methods do not consist hazardous effects and it is cheaper than the other methods, the public should be more informed by the media about the CAM methods' advantages and their potential negative interactions with drugs.

\section{References}

[1] Özçelik, H., and Fadıloğlu, C. 2009. "The Reason of Using CAM Methods by the Cancer Patients." The Turkish Oncology Journal 24 (1): 48-52.

[2] Y1ld1z, İ. 2006. "The Using of CAM by the Cancer Patients.” Ph.D. thesis, University of Istanbul.

[3] Oh, B., Butow, P., Mullan, B., Beale, P., Pavlakis, N., Rosenthal, D., and Clarke, S. 2010. "The Use and Perceived Benefits Resulting from the Use of Complementary and Alternative Medicine by Cancer Patients in Australia.” Asia-Pacific Journal of Clinical Oncology 6 (4): 342-9.

[4] Pihlak, R., Liivand, R., Trelin, O., Neissar, H., Peterson, I., Kivistik, S., Lilo, K. and Jaal, J. 2013. “Complementary 
Medicine Use among Cancer Patients Receiving Radiotherapy and Chemotherapy: Methods, Sources of Information and the Need for Counseling.” European Journal of Cancer Care (23) (2): 249-54.

[5] Klug, W. S., and Cummings, M. R., 2000. The Genetic Consept. Edited by Öner, C. Ankara: Palme Press, 816.

[6] Birol, L., Akdemir, N., and Bedük, T., 1997. The Nursing of Internal Medicine. Ankara: Vehbi Koç Foundation Press, 120.

[7] Algier, L. A., Hanoglu, Z., Ozden, G., and Kara, F. 2005. "The Use of Complementary and Alternative (non-Conventional) Medicine in Cancer Patients in Turkey.” European Journal of Oncology Nursing 9 (2): 138-46.

[8] Molassiotis, A., Panteli, V., Patiraki, E., Ozden, G., Platin, N., Madsen, E., Browall, M., Fernandez-Ortega, P., Pud, D., and Margulies, A. 2006. "Complementary and Alternative Medicine Use in Lung Cancer Patients in Eight European Countries.” Complementary Therapies in Clinical Practice 12 (1): 34-9.

[9] Pud, D., Kaner, E., Monag, A., Ben-Ami, S., and Yaffe, A. 2005. "Use of Complemantary and Alternative Medicine among Cancer Patients in Israel." European Journal of Oncology Nursing 9 (2): 124-30.

[10] Shumay, D. M., Gertrand, M. A., Kakai, H., and Gotay, C. C. 2001. "Why Some Cancer Patients Choose Complementary and Alternative Medicine Instead of Conventional Treatments." The Journal of Family Practise 50 (12): 1067.

[11] Kav, S., Hanoğlu, Z., and Algier, L. 2008. "The Using of CAM by the Cancer Patients in Turkey.” International Journal of Hematology and Oncology 18 (1): 32-8.

[12] Ben-Arye, E., Ali-Shtayeh, M. S., Nejmi, M., Schiff, E., Hassan, E., Mutafoglu, K. U., Afifi, F., Jamous, R. M., Lev, E., and Silbermman, M. 2012. "Integrative Oncology Research in the Middle East: Weaving Traditional and Complementary Medicine in Supportive Care.” Supportive Care in Cancer 20 (3): 557-64.

[13] Rausch, S. M., Winegardner, F., Kruk, K. M., Phatak, V., Wahner-Roedler, D. L., Bauer, B., and Vincent, A. 2011. "Complementary and Alternative Medicine: Use and
Disclosure in Radiation Oncology Community Practice.” Supportive Care in Cancer 19 (4): 521-9.

[14] Wanchai, A., Armer, J. M., and Stewart, B. R., "Thai Nurses' Perspectives on the Use of Complementary and Alternative Medicine among Thai Breast Cancer Survivors in Northern Thailand.” International Journal of Nursing Practise 2013 (Nov.). Accessed November 13, 2013. http://www.ncbi.nlm.nih.gov/pubmed/24219109.

[15] O’Connor, N., Graham, D., O’Meara, A., Devins, M., Jennings, V., O’Leary, D., and O’Reilly, M. 2013. “The Use of Complementary and Alternative Medicine by Irish Pediatric Cancer Patients.” Journal of Pediatric Hematology/Oncology 35 (7): 537-42.

[16] Tazi, I., Nafil, H., Mahmal, L., Harif, M., Khouchani, M., Saadi, Z., Belbaraka, R., Elomrani, A., and Tahri, A. 2013. "Complementary Medicine in Cancer Patients under Treatment in Marrakech, Morocco: A Prospective Study.” Bulletin of the Society of Exotic Pathology 106 (4): 278-85.

[17] Paul, M., Davey, B., Senf, B., Stoll, C., Münstedt, K., Mücke, R., Micke, O., Prott, F. J., Buentzel, J., and Hübner, J. 2013. "Patients with Advanced Cancer and Their Usage of Complementary and Alternative Medicine.” Journal of Cancer Research and Clinical Oncology 139 (9): 1515-22.

[18] Garland, S. N., Valentine, D., Desai, K., Li, S., Langer, C., Evans, T., and Mao, J. J. 2013. “CAM (Complementary and Alternative Medicine) Use and Benefit Finding among Cancer Patients.” Journal of Alternative and Complementary Medicine 19 (11): 876-81.

[19] Yarney, J., Donkor, A., Opoku, S. Y., Yarney, L., Agyeman-Duah, I., Abakah, A. C., and Asampong, E. 2013. "Characteristics of Users and Implications for the Use of Complementary and Alternative Medicine in Ghanaian Cancer Patients Undergoing Radiotherapy and Chemotherapy: A Cross-Sectional Study." BMC Complementary and Alternative Medicine 13 (Jan.): 16.

[20] Yang, C., Chien, L. Y., and Tai, C. J. 2008. "Use of Complementary and Alternative Medicine among Patients with Cancer Receiving Outpatients Chemotherapy in Taiwan.” Journal of Alternative and Complementary Medicine 14 (4): 413-6. 